\title{
Unilateral Periorbital Oedema with Hypothyroidism and Multinodular Goiter
}

\author{
Blerta Rama, Nishant Taneja, Nazmije Martinaj, Genc Shala, \\ Admir Sulovari, Naser Gjonbalaj
}

Department of Ophthalmology of Prishtina (Kosovo) and Tirana (Albania), Department of Internal Medicine and Rheumatology, Department Endocrinology, Radiology, Allergology, Infectiology, American Hospital Pristina, Prishtina, Kosovo

Email: Blerta.rama@uni-pr.edu

How to cite this paper: Rama, B., Taneja, N., Martinaj, N., Shala, G., Sulovari, A. and Gjonbalaj, N. (2021) Unilateral Periorbital Oedema with Hypothyroidism and Multinodular Goiter. Open Journal of Ophthalmology, 11, 229-239.

https://doi.org/10.4236/ojoph.2021.113018

Received: May 19, 2021

Accepted: August 6, 2021

Published: August 9, 2021

Copyright $\odot 2021$ by author(s) and Scientific Research Publishing Inc. This work is licensed under the Creative Commons Attribution International License (CC BY 4.0).

http://creativecommons.org/licenses/by/4.0/

\begin{abstract}
Thyroid associated ophthalmopathy is an autoimmune disorder which involves orbital and periorbital tissue. The immune-mediated inflammation of the orbital tissues can involve extraocular muscles, orbital connective tissue or orbital fat and periocular soft tissues. Bilateral involvement of thyroid associated orbitopathy is usually asymmetric, but unilateral thyroid associated orbitopathy has been less reported. Periorbital oedema as the only sign with hypothyroidism is uncommon and if present, it is more frequent bilaterally present and no cases are evidenced as unilateral. Pitting oedema in hypothyroidism is rare and can be due to increased capillary permeability, decreased adrenergic tone and increase in serotonin metabolism. Unilateral periorbital and eyelid oedema can associate with various clinical entities, multidisciplinary team is necessary to exclude the concomitant disease, so the patient can immediately be treated with proper therapy. We represent the case of unusually unilateral recurrent periorbital oedema in the period of time for 3 years with stabilized primary hypothyroidism and multinodular goitre.
\end{abstract}

\section{Keywords}

Thyroid Associated Ophthalmopathy, Hypothyroidism, Periorbital Oedema

\section{Introduction}

Thyroid associated ophthalmopathy is an autoimmune disorder which involves orbital and periorbital tissue, although the clear mechanism is not clearly understood. Thyroid associated ophthalmopathy is the most common in Graves' disease, but it also occurs in hypothyroid and euthyroid patients [1]. Thyroid associated ophthalmopathy (TAO) is associated in $80 \%$ of the cases with 
Graves's disease (the most common cause of hyperthyroidism), with thyroid cancers or autoimmune hypothyroid due to Hashimoto's thyroiditis in $10 \%$ of the patients and with no thyroid disease $10 \%$ of cases [2]. The immune-mediated inflammation of the orbital tissues can involve extraocular muscles, orbital connective tissue or orbital fat and periocular soft tissues [3]. TAO has a wide range of clinical signs as eyelid retraction, proptosis, restrictive myopathy, dysthyroid optic neuropathy, pitting eyelid oedema, conjunctival chemosis and redness [3]. The diagnosis can be particularly difficult in case with unilateral presence of the clinical signs. Bilateral involvement of TAO can be asymmetric, but unilateral TAO has been reported in only $9 \%-15 \%$ of cases [4]. Asymmetry in the clinical ocular signs was found more commonly in hypothyroid or euthyroid TAO and was rare in hyperthyroid [4] [5]. Periorbital oedema with hypothyroidism is uncommon and it initially mimics other diseases [6]. There are many case reports of unilateral proptosis and unilateral extraocular muscle enlargement with acute hypothyroidism presenting as bilateral eyelid swelling, but there is scarcity of cases with unilateral periorbital edema with hypothyroid goitre [1] [6] [7].

In order to exclude the various entities that can cause unilateral eyelid oedema, we need multidisciplinary team and also advanced facilities of laboratory investigations and imaging.

We represent the case of unusual case of unilateral pitting periorbital oedema that showed off and on exacerbations over a period of time for 3 years even with stabilized primary hypothyroidism and multinodular goitre. The purpose is to emphasize the exclusion of the concomitant diagnoses and evaluation of the less frequent clinical cases.

\section{Case Report}

We represent the case of the unilateral recurrent periorbital oedema in patient with primary hypothyroidism and multinodular goiter. A 57 years old female patient was presented in our clinic with periorbital oedema of the right side for 3 weeks. The patient was on systemic antibiotics for 4 days without improvement. The periorbital oedema was pitting, non-erythematous and painless (Figure 1) photo from patient. The periorbital oedema was recurrent last 3 years with the same clinic overview, but the cranio-orbital MRI was made only in the first year as described on the right side in the periorbital soft tissues are observed edematous changes expressed especially along the lateral aspect of the orbit that go in favor of periorbital cellulite (Figure 2). CT of paranasal sinus and radiography of paranasal structures were within with physiological limits.

Ophthalmological examination showed visual acuity OD: 0.9 sc Snellen chart and OS: 1.0sc. Normal intraocular pressure, IOP of the OD: $15.0 \mathrm{mmHg}$ and OS IOP: $14.0 \mathrm{mmHg}$ and nasolacrimal system irritation test both passable. Negative afferent pupillary defect and fundus examination were within normal limits associated with OCT of optic nerve and macula evaluation confirming the absence of the possible pathologies (Figure 3) (Figure 4). Visual field was normal (Figure 5) 


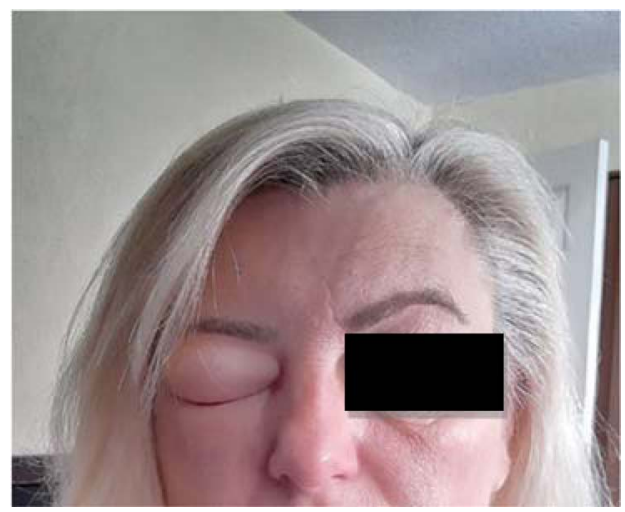

Figure 1. Pitting, non-erythematous and painless periorbital oedema.

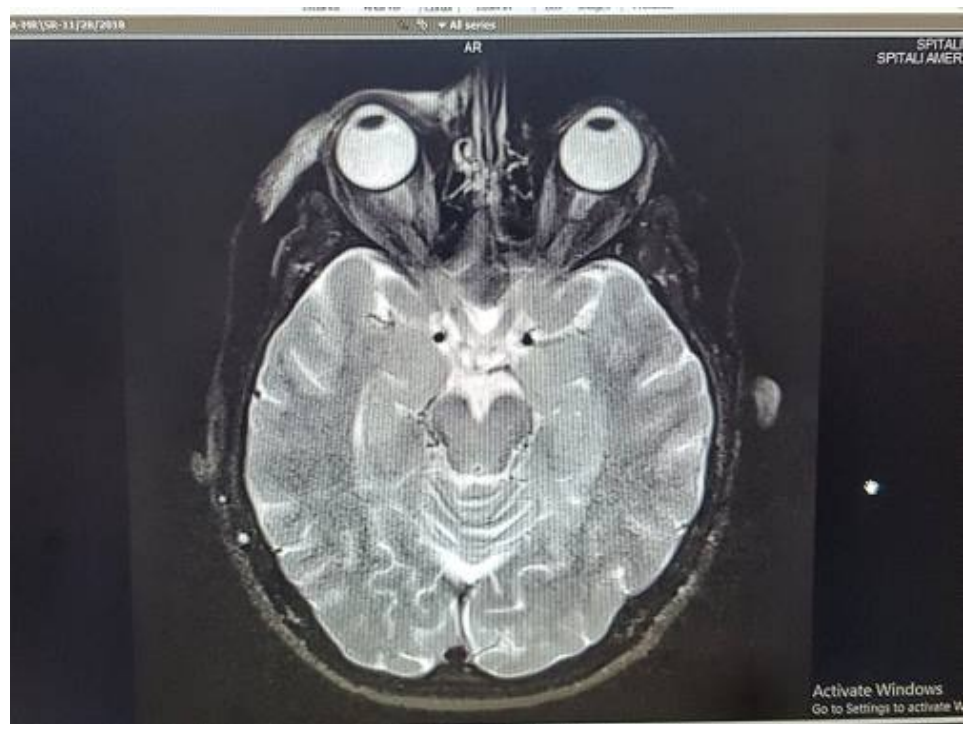

Figure 2. Periorbital soft tissues with edematous changes.

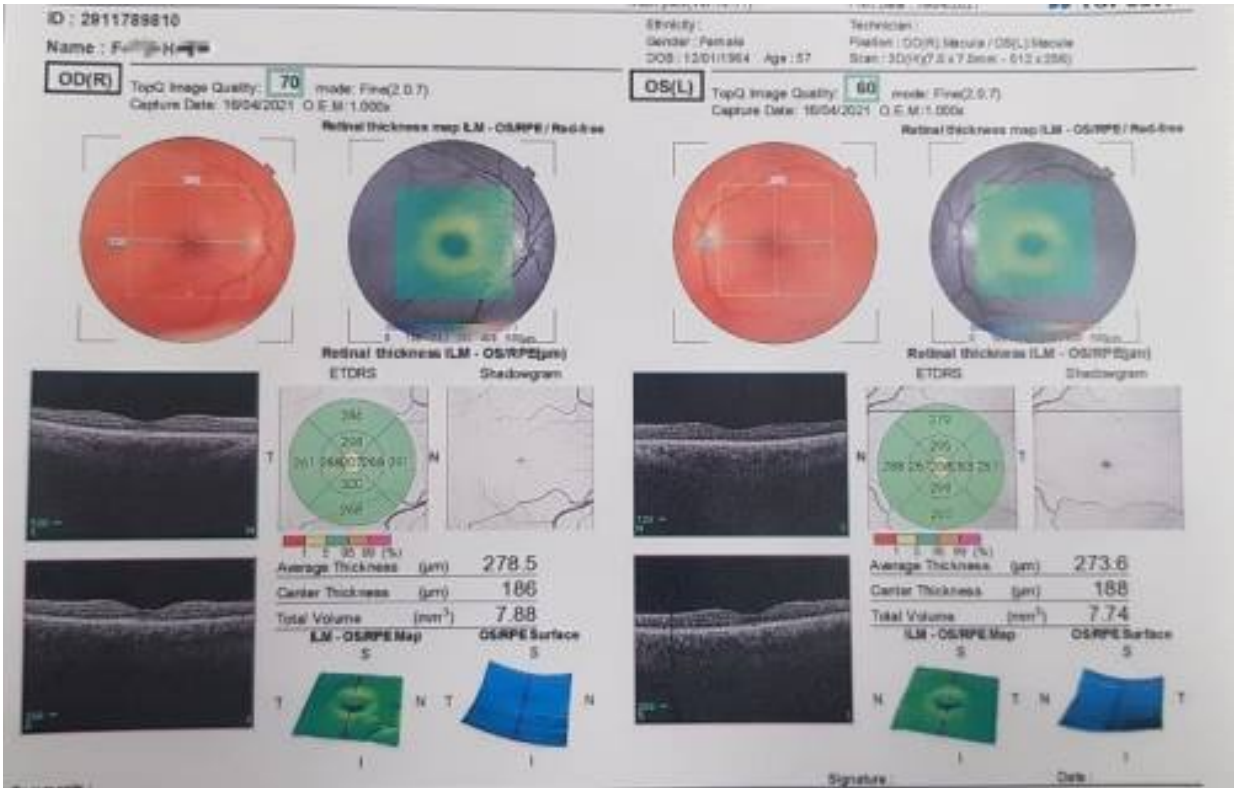

Figure 3. Macular optical coherence tomography of the both eye. 


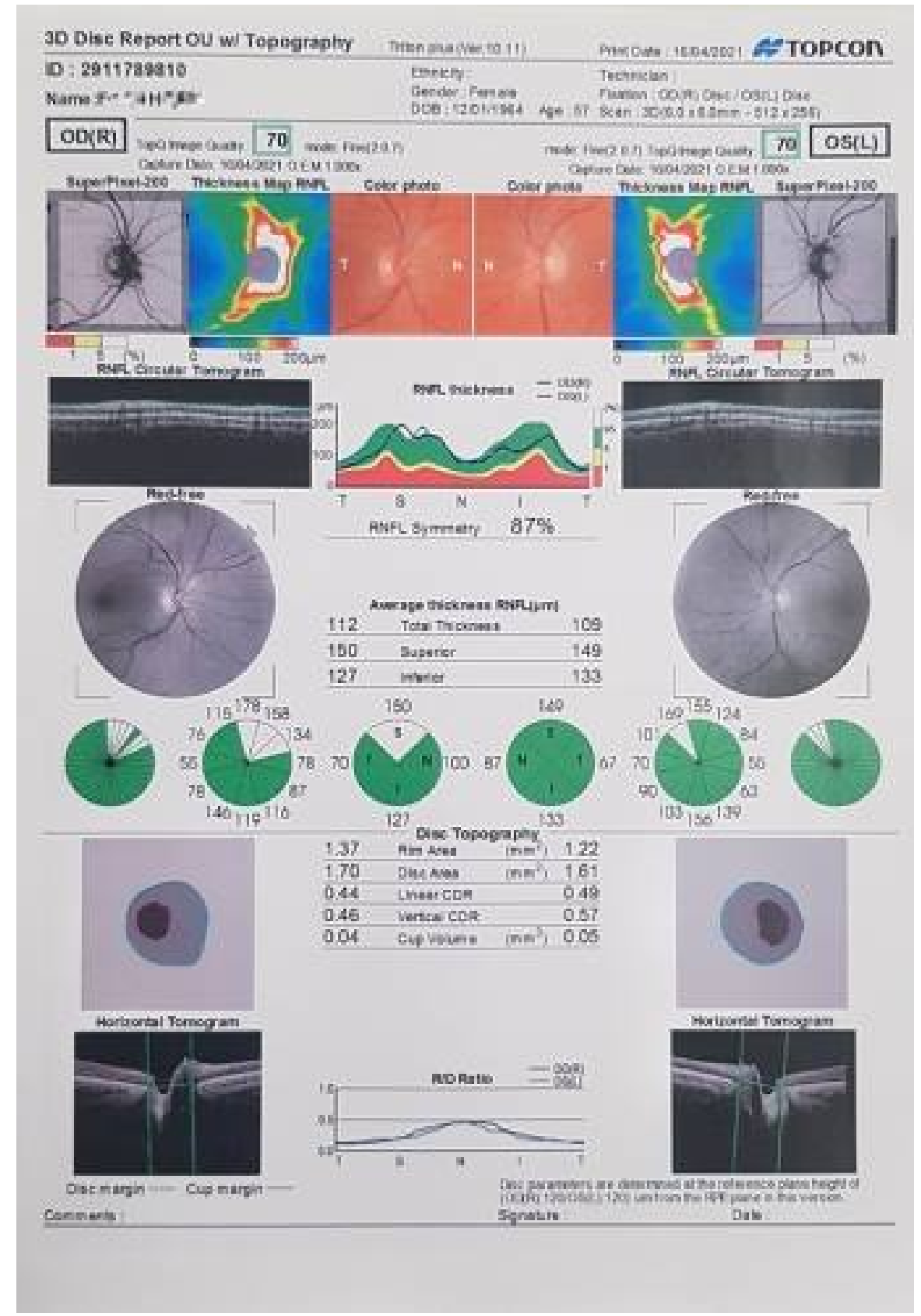

Figure 4. Optic nerve OCT of the both eyes.

Eye motility of the both eye normal and B scan eye echography revealed small presence of the opacities in $\mathrm{CV}$, but chorioretina normal and no orbital pathologies were detected (Figure 6).

Periorbita, palpebrae and anterior segment of the left eye were normal, but the right side only periorbital edema with slight hyperemic conjunctiva with no other ocular involvement was evident. The periorbital and palpebral oedema was pitting, cold and painless closing the eye completely, limiting the active and passive movements of the eyelids entirely.

She was diagnosed with HTA for 20 years treating with medicaments, 


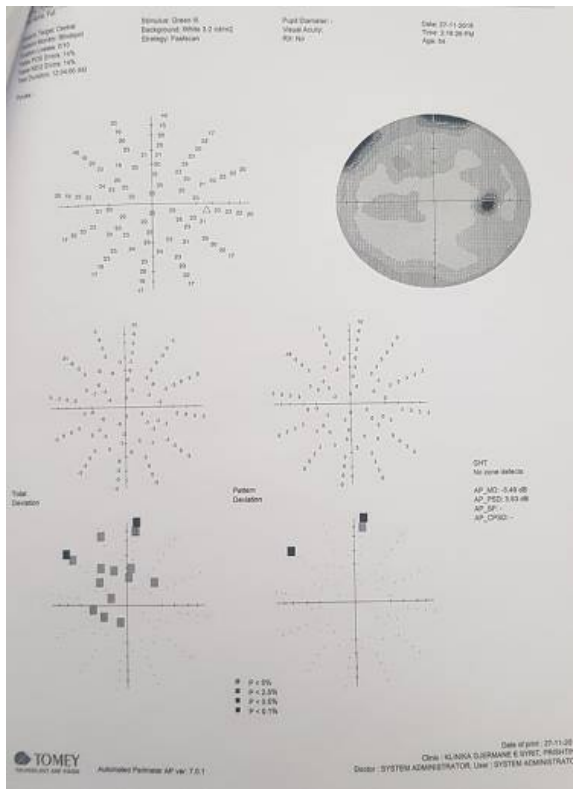

(a) right eye

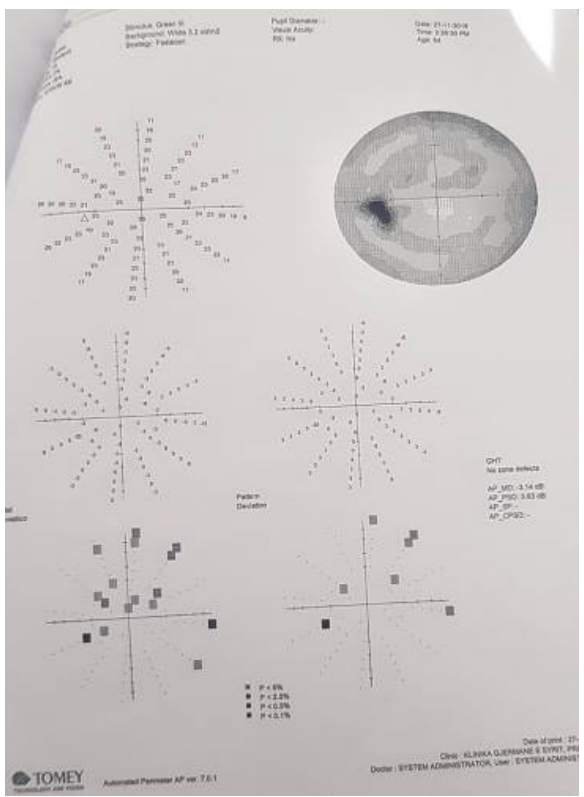

(b) left eye

Figure 5. Visual field of the both eyes.

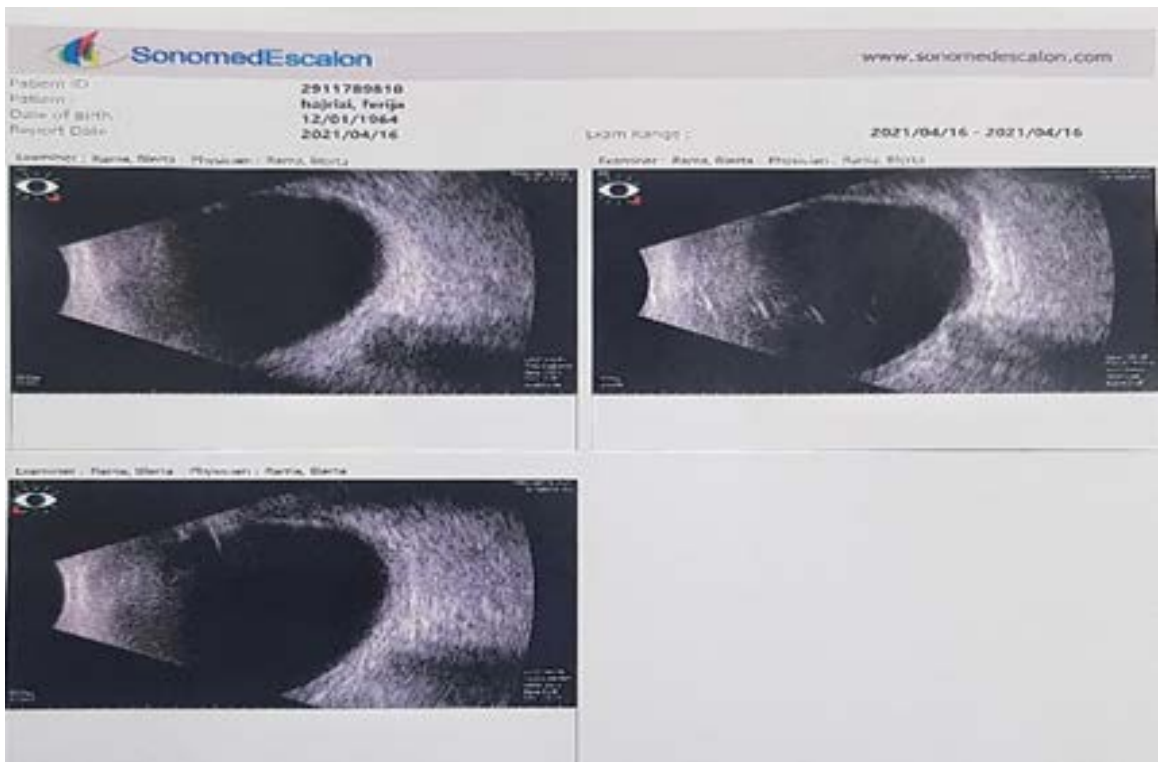

Figure 6. B scan of both eyes.

$130 / 80 \mathrm{mmHg}$ currently and primary hypothyroidism for 3 years treating the disease as well. Denies any allergies on food or medicaments, non-smoker and does not drink alcohol.

Although laboratory tests revealed CRP $=2.20 \mathrm{mg} / \mathrm{L}$ normal, $\mathrm{SE}=16 \mathrm{~mm} / \mathrm{hr}$ normal values, the patient was put on the systemic antibiotics for 4 days before visiting us, but with no improvement. On the first represented periorbital oedema in 2018 the patient treated as preseptal cellulitis and was recovered with oral and intravenous antibiotics, with oral and intravenous antihistaminic, local augment with antibiotic-corticosteroids and vitamin $\mathrm{C}$ tablets. On second attack 
the patient has used only systemic corticosteroids $20 \mathrm{mg}$ orally which recovered the oedema. The third unilateral periorbital and palpebral oedema with no other ocular association lead the necessity to do other laboratory test as on Table 1, as well as more specific laboratory test on Table 2 .

Urine was as following negative bilirubin, urobilina, glucose, acetone, renal epithelia's, yalin cylinder, granule cylinder, nitrite, no proteinuria, normal density, color and smell, normal reaction and transparency, slightly elevated erythrocyte 4 - 6 ( 0 - 4 norm $)$ and leukocytes 3 - 4 (0 - 2 norm). Creatinemia was $0.81 \mathrm{mg} / \mathrm{dl}$ normal limits.

According to the thyroid glandular test hypothyroidism was stabilised over these 3 years as described on Table 3 .

Ultrasound of the thyroid glandule showed the presence of the already previously diagnosed multinodular bilateral goiter as well, but glandular thyroid biopsy confirmed no atypia present.

The patient was treated only with local antibiotic-corticosteroid eye drops 4 times 2 drops for 1-week, artificial tears 4 times 2 drops and local antibiotic augment once a day before sleep for 1 week. The patient came after one week for a visit with total recovery and no sign and symptoms present (Figure 7). Few days later the signs and symptoms started to appear again (Figure 8), when the topical

Table 1. laboratory tests.

\begin{tabular}{|c|c|c|}
\hline Parameter & Results & Normal ranges \\
\hline CRP & $2.8 \mathrm{mg} / \mathrm{L}$ & $0-5$ \\
\hline Glucose & $99.00 \mathrm{mg} / \mathrm{dl}$ & $70-105$ \\
\hline Rheumatic factor & $24.60 \mathrm{UI} / \mathrm{ml}$ & $0-30$ norm, 30 - 50 slightly positive, $>50$ positive \\
\hline fibrinogen & $4.34 \mathrm{~g} / \mathrm{L}$ & $2-4$ \\
\hline ac. Anti-nuclear (ANA) & $0.5 \mathrm{U} / \mathrm{L}$ & $<1.0$ negative, $1.1-1.2$ intermediary, $>1.2$ positive \\
\hline ac. Anti ENA-RNP & $7.4 \mathrm{U} / \mathrm{mL}$ & $<15.0$ negative, $15.1-25.0$ intermediary, $>25.1$ positive \\
\hline pANCA & $1.3 \mathrm{U} / \mathrm{mL}$ & $<5.0$ \\
\hline cANCA & $1.6 \mathrm{U} / \mathrm{mL}$ & $<5.0$ \\
\hline SSA/Ro & $3.2 \mathrm{U} / \mathrm{mL}$ & $<15.0$ negative, $15.1-25.0$ intermediary, $>25.1$ positive \\
\hline $\mathrm{SSB} / \mathrm{La}$ & $0.1 \mathrm{U} / \mathrm{mL}$ & $<15.0$ negative, $15.1-25.0$ intermediary, $>25.1$ positive \\
\hline cholesterolemia & $246 \mathrm{mg} / \mathrm{dl}$ & $0-200$ high \\
\hline triglyceride & $159 \mathrm{mg} / \mathrm{dl}$ & $0-200$ \\
\hline LDL cholesterol & $195 \mathrm{mg} / \mathrm{dl}$ & $\begin{array}{c}0-100 \text { no risk CV, } 100-129 \text { low risk CV, } \\
>129 \text { high risk CV, high }\end{array}$ \\
\hline HDL cholesterol & $59 \mathrm{mg} / \mathrm{dl}$ & $>65$, low \\
\hline VLDL & $31.80 \mathrm{mg} / \mathrm{dl}$ & $0-30$, high \\
\hline Vitamin $25(\mathrm{OH}) \mathrm{D} 3$ & $30.7 \mathrm{ng} / \mathrm{mL}$ & $\begin{array}{c}<8 \text { low, } 8.0-20.0 \text { insufficient, } 21.0-60.0 \text { optimale, } \\
61.0-90.0 \text { high, }>140.0 \text { toxic }\end{array}$ \\
\hline
\end{tabular}


Table 2. Specific laboratory tests.

\begin{tabular}{ccc}
\hline Parameter & Results & Normal ranges \\
PT & $91.70 \%$ & $70-120$ no therapy, \\
INR & $1.06 \%$ & $25-35$ with anticoagulant therapy \\
APTT & 27.00 seconds & $0.9-1.2$ no therapy, \\
HbA1c & $5.30 \%$ & $2-3$ with anticoagulant therapy \\
Fe in blood & $117.00 \mathrm{ug} / \mathrm{dl}$ & $<5-40$ \\
ALT (SGPT) & $35.00 \mathrm{U} / \mathrm{L}$ & $00-55$ \\
AST(SGOT) & $22.00 \mathrm{U} / \mathrm{L}$ & $5-34$ \\
vitamin B12 & $332.00 \mathrm{pg} / \mathrm{mL}$ & $187-883$ \\
IgE & $35.30 \mathrm{IU} / \mathrm{ml}$ & $<100$ \\
ac. Anti-H.pylori-IgG & $0.70 \mathrm{U} / \mathrm{mL}$ & $<20$ negative, $20-25$ on limits, $>25$ positive \\
ac. Anti-H.pylori-IgA & $19.1 \mathrm{U} / \mathrm{mL}$ negative & $<20$ negative, $20-25$ on limits, $>25$ positive \\
Antibodies Anti-Sars-Cov- 2 & $0.066 \mathrm{COI}$ & $0-1$ negative, $>1$ positive \\
Conjunctival smear & sterile & $/$ \\
\hline
\end{tabular}

Table 3. Thyroid glandular tests over the period of time of 3 years.

\begin{tabular}{cccc}
\hline 1 year & 2 year & 3 year & Normal ranges \\
\hline $\mathrm{T} 4=13.1 \mathrm{pmol} / \mathrm{L}$ & $\mathrm{T} 4=11.4 \mathrm{pmol} / \mathrm{L}$ & $\mathrm{FT} 4=1.11 \mathrm{ng} / \mathrm{dl}$ & $10.3-23.1$ \\
$\mathrm{TSH}=3.13 \mathrm{uIU} / \mathrm{ML}$ & $\mathrm{TSH}=\begin{array}{c}5.62 \mathrm{uIU} / \mathrm{mL}, \\
\text { high }\end{array}$ & $\mathrm{TSH}=2.66 \mathrm{uIU} / \mathrm{mL}$ & $\mathbf{0 . 4 0 - 4 . 0}$ \\
$\mathrm{Tg}($ Tireoglobuline $)$ & $\mathrm{Tg}=212.0 \mathrm{ng} / \mathrm{mL}, \mathrm{high}$ & $\mathrm{Tg}=194.9 \mathrm{ng} / \mathrm{mL}, \mathrm{high}$ & $1.7-56.0$ \\
$=113.0 \mathrm{ng} / \mathrm{mL}$, high & $/$ & $\mathrm{CAL}=31.0 \mathrm{pg} / \mathrm{mL}, \mathrm{high}$ & $<11.5$ \\
$\mathrm{CAL}($ Calcitonine $)=1.0 \mathrm{pg} / \mathrm{mL}$ & & &
\end{tabular}

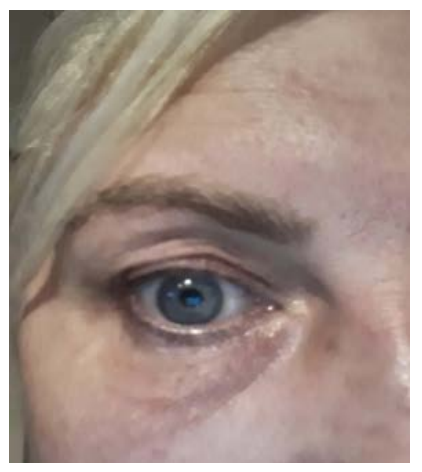

Figure 7. 1 week total recovery.

antibiotic and steroids 4 times a day, artificial tears 4 times a day and systemic steroids were prescribed as following; prednisone $20 \mathrm{mg} 1 \times 1$ in the morning $(7-8$ h) for 5 days, $10 \mathrm{mg} 1 \times 1$ in the morning $(7-8 \mathrm{~h}$ ) for 5 days, $5 \mathrm{mg} 1 \times 1$ in the morning $(7-8 \mathrm{~h}$ ) for 5 days and Pantoprazole $40 \mathrm{mg} 1 \times 1$ before the breakfast, and the results were present within days (Figure 9). 


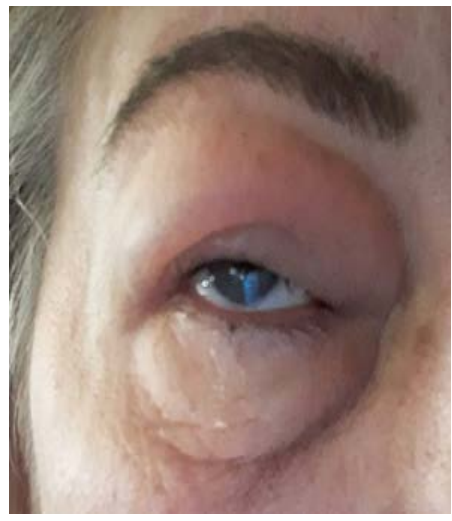

Figure 8. Reccurent sign and symptoms.

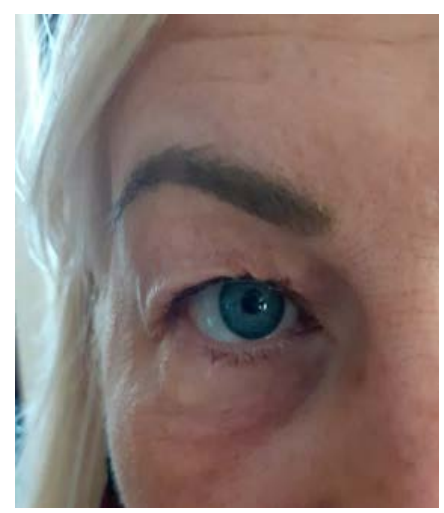

Figure 9. Patient after adding the topical therapy within days after systemic steroids.

The patient is on follow up every 3 months for evaluation of the hypothyroidism and mult-inodular goitre with ocular treatment if periorbital oedema reoccurs.

\section{Discussion}

TAO is not clearly understood, but it has been confirmed that the autoimmunity develops antigens common to the thyroid gland and the orbit. Recent studies have reported the up reguation of the cardiac calsequestrin gene in TAO patient and autobodies against orbital fibroblast membrane antigen collagen XIII as well [8] [9]. In hypothyroidism accumulation the mucopolysacharides and water in the dermis were causes because of the reduced activity of enzymes in the cholesterol sulfate cycle, causing the changes in the skin barrier and increased capillary permeability, decreased androgenic tone and increased serotonin metabolism [10] [11].

Pitting eyelid oedema in hypothyroidism is rare and bilateral eyelid oedema is not a common clinical sign. Moreover, unilateral periorbital oedema as a single ocular clinical sign in hypothyroidism is not evidenced. Therefore, differential diagnosis of the eyelid swelling can be complex and it requires careful physical and laboratory examination to exclude inflammatory and non-inflammatory causes. 
First periorbital oedema was treated with local and systemic antibiotics doubting for preseptal cellulitis, where paranasal structure inflammations were excluded. There was no other clinical sign that could lead to the idiopathic orbital inflammation, as one of the most common inflammatory condition mimicking TAO and orbital tissues [12]. Sterile conjunctival smear emphases the lack of infection. Autoimmune vasculitis, rheumatic arthritis, systemic lupus erythematous, hypovitaminosis D and B12, nephrotic syndrome, diabetes mellitus, bleeding or clotting disorders, hepatic diseases, gastric infection with $H$. $p y$ lori were excluded with the specific test and more important for the moment, Covid-19 negative test.

Recognising eyelid oedema can be in differential diagnosis with pre or postoperative oedema with systemic implications as allergies, Ocular rosacea, Melkersson Rosenthal Syndrome, Floppy Eyelid Sydrome, Cold urticaria, Lymphedema, eyelid-dependent Keratoconjunctivitis sicca, all of which were excluded in our case. C1-Esterase Inhibitor Deficiency-Type Angi oedema as one of the cases was not tested, according the age 57 years and pitting oedema the diagnosis was not evaluated [13]. Blepharochalsis, although very similar, it is a rare form of eyelid oedema which can be unilateral, with initial symptoms unset at an age of 11 years old non pitting oedema ending hypervascular and with hyperpigmentation [14] [15]. Mononucleosis was excluded by infectiologist. Medication induced eyelid oedema was absent as well [13].

Finally recurrent unilateral periorbital oedema in hypothyroidism with goitre was diagnosed. Eyelid oedema requires meticulous clinical workup evaluation all the local and systemic diseases, especially when unusual cases present, in order to find the proper cause and start the appropriate treatment. Thyroid associated orbitopathy in hypothyroidism with goitre requires levothyroxine therapy and medical treatment with systemic steroids, orbital radiotherapy and immunosuppressive therapy [3]. Steroids are the best treatment for active TAO, but mild and less severe ophthalmopathies often does not require the treatment as they have spontaneously recovery [3].

\section{Conclusion}

Periorbital and eyelid oedema is a common clinical sign of lots of systemic diseases and local eye pathologies. More common is bilateral periorbital oedema, but unilateral periorbital oedema is recorded in some of the diseases. Unilateral periorbital oedema with no other ocular associations in hypothyroidism with goitre is rarely evidenced. Therefore, the connection between the clinical sign and the disease needs the exclusion of all the possible causes previously. Recurrence, closure and oedema of the eye can lead to patient's anxiety and disbelief and delay of the proper treatment. Arterial hypertension, as already existing disease, should be monitored. Systemic steroid therapy should be started cautiously with the hypothyroidism therapy and follow up of the multinodular goiter. 


\section{Conflicts of Interest}

The authors declare no conflicts of interest regarding the publication of this paper.

\section{References}

[1] El Othman, R., Ephrem, C., Touma, E., Hallit, S. and El Othman, R. (2020) A Case Report of Thyroid-Associated Orbitopathy with Elevated TPO Antibodies. BMC Endocrine Disorders, 20, Article No. 176. https://doi.org/10.1186/s12902-020-00658-6

[2] Bartalena, L., Pinchera, A. and Marcocci, C. (2000) Management of Graves' Ophthalmopathy: Reality and Perspectives. Endocrine Reviews, 21, 168-199. https://doi.org/10.1210/edrv.21.2.0393

[3] Şahlı, E. and Gündüz, K. (2017) Thyroid-Associated Ophthalmopathy. Turkish Journal of Ophthalmology, 47, 94-105. https://doi.org/10.4274/tjo.80688

[4] Kashkouli, M., Kaghazkanani, R., Heydari, I., et al. (2011) Bilateral Versus Unilateral Thyroid Eye Disease. Indian Journal of Ophthalmology, 59, 363-366. https://doi.org/10.4103/0301-4738.83612

[5] Eckstein, A.K., Lösch, C., Glowacka, D., et al. (2009) Euthyroid and Primarily Hypothyroid Patients Develop Milder and Significantly More Asymmetrical Graves Ophthalmopathy. British Journal of Ophthalmology, 93, 1052-1056. https://doi.org/10.1136/bjo.2007.137265

[6] Salazar-Nievas, M. and Arias-Santiago, S. (2013) Bilateral Eyelid Swelling Associated with Acute Hypothyroidism. Actas Dermo-Sifiliográficas, 105, 427-429. https://doi.org/10.1016/j.adengl.2013.05.009

[7] Daumerie, C., Duprez, T. and Boschi, A. (2008) Long-Term Multidisciplinary Follow-Up of Unilateral Thyroid-Associated Orbitopathy. European Journal of Internal Medicine, 19, 531-536. https://doi.org/10.1016/j.ejim.2008.01.013

[8] Gopinath, B., Wescombe, L., Nguyen, B. and Wall, J.R. (2009) Can Autoimmunity against Calsequestrin Explain the Eye and Eyelid Muscle Inflammation of Thyroid Eye Disease? Orbit, 28, 256-261. https://doi.org/10.1080/01676830903104629

[9] Wall, J.R. and Lahooti, H. (2010) Pathogenesis of Thyroid Eye Disease--Does Autoimmunity against the TSH Receptor Explain all Cases? Endokrynologia Polska, 61, 222-227.

[10] Cianfarani, F., Baldini, E., Cavalli, A., et al. (2010) TSH Receptor and Thyroid-Specific Gene Expression in Human Skin. Journal of Investigative Dermatology, 130, 93-101. https://doi.org/10.1038/jid.2009.180

[11] Mahajan, S.K., et al. (2021) Pitting Oedema in Hypothyroidism. Journal of Association of Physicians of India, 51, 885.

https://www.japi.org/v2d454b4/pitting-oedema-in-hypothyroidism

[12] Marinò, M., Ionni, I., Lanzolla, G., et al. (2020) Orbital Diseases Mimicking Graves' Orbitopathy: A Long-Standing Challenge in Differential Diagnosis. Journal of Endocrinological Investigation, 43, 401-411. https://doi.org/10.1007/s40618-019-01141-3

[13] Sami, M.S., Soparkar, C.N.S., Patrinely, J.R. and Tower, R.N. (2007) Eyelid Edema. Seminars in Plastic Surgery, 21, 24-31. https://doi.org/10.1055/s-2007-967744

[14] Dworak, D.P., Patel, S.A. and Thompson, L.S. (2017) An Unusual Case of Blepha- 
rochalasis. Journal of Ophthalmic and Vision Research, 12, 342-344.

[15] Koursh, D.M., Modjtahedi, S.P., Selva, D. and Leibovitch, I. (2009) The Blepharochalasis Syndrome. Survey of Ophthalmology, 54, 235-244.

https://doi.org/10.1016/j.survophthal.2008.12.005 